\title{
Conflictividad social y servicios públicos: El caso de la huelga de 1928 de los obreros de la Compañía General de Tranvías Eléctricos de Rosario (Argentina)
}

\author{
Social conflict and public services: The case of the 1928 strike by the workers of the \\ Compañia General de Tranvías Eléctricos de Rosario (Argentina)
}

\author{
Natalia Daniela Alarcón*
}

\begin{abstract}
Resumen: El importante ciclo de conflictividad social que se abre en 1928 en la ciudad de Rosario tiene entre sus numerosas huelgas algunas que implicaron al personal de diversas empresas concesionarias de servicios públicos entre ellas se encuentra la de los obreros de la Compañía General de Tranvías Eléctricos de Rosario (CGTER). El objetivo de este trabajo se abocará a revisitar tanto el desarrollo específico del conflicto tranviario de julio de 1928, el cual mantuvo en vilo a la ciudad durante casi un mes, perturbando en gran medida la vida cotidiana de la población al afectar el principal medio de locomoción de la urbe, como así también, el abanico de relaciones que se establecerán entre la empresa concesionaria, los trabajadores, el Jefe de policía y el Concejo Deliberante de la ciudad de Rosario, lo que nos permitirá visibilizar cómo el conflicto obrero se entrelaza con los devenires de la política local, provincial y en ciertos momentos nacional.
\end{abstract}

Palabras claves: huelga; obreros tranviarios; Concejo Deliberante; política; Rosario

\begin{abstract}
The important cycle of social unrest that began in 1928 in the city of Rosario has numerous strikes which involving the personnel of concessionaires of public services, among them the strike of the workers of Compañia General de Tranvias Eléctricos de Rosario (CGTER). The objective of this paper is the historical reconstruction of the tram workers strike which kept the city in suspense for almost a month, greatly disrupting the daily life of the population by affecting the main means of transport of the city, as well as, the range of relationships established between the concessionaire, the workers, the Chief of Police and the Deliberative Council of the city of Rosario, which will allow us to visualize how the labor conflict will intersect with the becoming of local, provincial and, at times, national politics.
\end{abstract}

Keywords: strike; tram workers; Deliberative Council; politics; Rosario

Recibido: 17 junio 2019 Aceptado: 12 septiembre 2019

\footnotetext{
* Argentina. Licenciada en Historia por la Universidad Nacional de Rosario. Este artículo es producto de la investigación que realiza la autora para su tesis doctoral. https:/ /orcid.org/0000-0003-2103-4042 Correo: natalia_alarcon_85@hotmail.com
} 


\section{Introducción}

El año 1928 fue un momento crucial en la historia del movimiento obrero argentino, ya que marcó la reactivación de la conflictividad social, de la cual la ciudad de Rosario no fue la excepción.

De las numerosas huelgas que estallaron en dicha urbe a lo largo de $1928^{1}$ y que afectaron a los servicios públicos, el paro de actividades del personal de la Compañía General de Tranvías Eléctricos de Rosario (CGTER) presentó sus particularidades, ya que se constituyó en un campo de disputa en donde intervinieron diversos actores, no sólo se circunscribió a los trabajadores y a la empresa concesionaria, sino que también incluirá a representantes del poder político local, planteándose por primera vez la posibilidad de la municipalización de los servicios públicos de la ciudad.

Si bien en los últimos años esta coyuntura ha sido intensamente trabajada, no por ello, la profusión de trabajos hace que este complejo periodo que se vive en la ciudad de Rosario y la provincia de Santa Fe haya sido agotado.

Por un lado, podemos encontrar trabajos que desde perspectivas renovadoras han abordado el conflicto en su matriz social y urbana, recuperando las características que tuvo la movilización proletaria que determinó el desarrollo positivo de la huelga de estibadores portuarios de 1928, destacando este hecho como un momento fundante que marcó el fortalecimiento de las organizaciones sindicales obreras a finales de los veinte. ${ }^{2}$ Deben sumarse también, los aportes de aquellos que estudian el rol jugado por la prensa en los conflictos, en la construcción de opinión pública contribuyendo a poner el foco de atención en cómo influyeron, en términos políticos, las opiniones volcadas en los periódicos. ${ }^{3}$

Desde el plano rural, los conflictos obreros en el campo del sur santafesino han sido estudiados profundamente a partir de un enfoque a largo plazo, otorgando un panorama que por su extensión territorial y particular apego a tomar en consideración los procesos

\footnotetext{
1 De mayo a noviembre de 1928 se declaran en total en la ciudad de Rosario: la huelga de los trabajadores del puerto; de la fábrica de Tejidos "La Americana" (12/06/28-14/08/28); de la Refinería Argentina (18/06/2805/07/28); de los fideeros de la Casa Minetti (20/06/28- 6/07/28); la huelga de los conductores de carros (25/06/28-15/07/28); de los obreros tranviarios (05/06/28-01/08/28); de los obreros y empleados de la Unión Telefónica (12/07/28-01/09/28); de los obreros de las Aguas Corrientes (16/07/28); de la Fábrica de Bolsas (20/07/28-03/08/28); de los obreros Metalúrgicos (25/07/28); huelga de los obreros de la Sociedad de Electricidad (18/07/28-04/08/28); obreros panaderos (27/07/28-02/08/28); de los obreros pavimentadores (30/07/28-29/08/28); de los choferes de ómnibus (08/08/28-02/09/28), huelga de los ebanistas y anexos (21/08/28-27/09/28); de Albañiles y anexos (26/08/28-03/09/28); de los obreros carpinteros; de los obreros de implementos agrícolas (07/09/28-08/08/28); huelga de los metalúrgicos de la Casa Chaina y Cía. (08/09/2809/08/28); de los obreros de la Empresa de Gas (08/09/28-11/08/28), de los repartidores de hielo (06/08/2808/11/28); huelga de los obreros cerveceros Schlau (08/11/28-13/11/28); de los obreros Gráficos (13/11/28); de los obreros aserradores (28/05/28-29/07/28) y de los obreros Mosaistas (14/11/28).

2 Paulo Menotti y Oscar Videla, “Las huelgas de los estibadores portuarios en el sur santafesino en 1928”, en Sociohistórica, No 32, 2 do. Semestre de 2013. Disponible en: http:/ / www.sociohistorica.fahce.unlp.edu.ar/

3 Fernando Cesaretti, Diego Mauro y Hernán Uliana, “Representaciones, prensa y conflicto social. Estrategias complejas en el diario La Capital, mayo - julio de 1928", en Marta Bonaudo (dir.) Imaginarios y prácticas de un orden burgués. Rosario, 1850 - 1930, Los actores entre las palabras y las cosas, Rosario, Prohistoria, 2005. Marianela Scocco, Representaciones de la huelga de portuarios. Rosario, mayo de 1928. Una perspectiva desde el acontecimiento, Seminario Regional, Escuela de Historia, Rosario, UNR, 2009.
} 
locales se constituyen en trabajos directrices para abordar no sólo a sindicatos implicados sino también a las orientaciones ideológicas que convivieron y compitieron en su seno. ${ }^{4}$

Incluso diversos trabajos entre los que se incluye la producción de esta autora, que abordan el periodo a partir del análisis del comportamiento de las corporaciones empresarias rosarinas frente a la conflictividad social han contribuido al enriquecimiento sobre el estudio de esta coyuntura. ${ }^{5}$

Al mismo tiempo, existen trabajos que poniendo específicamente el foco de interés en las huelgas de servicios públicos, como la de los trabajadores telefónicos busca explicitar el comportamiento de las corporaciones empresariales ante este conflicto, intentando dilucidar como actores políticos y corporativos incluirán, de una manera novedosa, en la agenda pública tópicos de un discurso con fuertes argumentos anti-imperialistas frente al capital extranjero instalado en el país, encarnado en este caso por la Unión Telefónica. 6

Por otro lado, las huelgas de los obreros tranviarios que se desarrollaron entre los años 1928/1929 han sido estudiadas por Adriana Pons, dicha autora ha analizado los pliegos de reivindicaciones presentados por los trabajadores, la actitud de la empresa de capital belga, la relación de ambos actores con el poder municipal, provincial y con otras instancias sociales en su contextualización específica. Sopesando los intereses en conflicto, y la actitud gubernamental que osciló entre la coacción y la búsqueda de consenso. ${ }^{7}$

En este sentido, el objetivo del trabajo es revisitar tanto el desarrollo específico del conflicto tranviario de julio de 1928, como así también, el abanico de relaciones que se establecieron entre la empresa concesionaria, los trabajadores, el Jefe de policía y el Concejo Deliberante de la ciudad de Rosario, permitiéndonos visibilizar cómo el conflicto obrero se entrelaza con los devenires de la política local, provincial y en ciertos momentos nacional.

En primer lugar, se busca caracterizar las diversas corrientes que operaban en el movimiento obrero de la ciudad de Rosario, para luego contextualizar la particular coyuntura del año 1928 tanto a nivel, local como provincial y nacional. En segundo lugar, se abordará en específico, cómo estaba conformada la estructura de servicios públicos de la urbe rosarina, focalizando en el sistema de concesiones y el papel jugado durante periodos previos por la Compañía General de Tranvías Eléctricos de Rosario. Para luego, abocarnos

\footnotetext{
4 Adrián Ascolani, El sindicalismo rural en la Argentina. De la resistencia clasista a la comunidad organizada (19281952), Bernal, UNQ, 2009. Eduardo Sartelli, "Mecanización y conflicto social en la llanura pampeana. Santa Fe y la huelga de braceros en 1928", en Adrián Ascolani, (comp.) Historias del sur santafesino, Rosario, Ed. Platino, 1993.

5 Natalia Alarcón, "Corporaciones empresarias, politica y conflicto obrero en los prolegómenos de la crisis", Tesis de Licenciatura, Escuela de Historia, Facultad de Humanidades y Artes, Universidad Nacional de Rosario, 2017. Silvia Simonassi y Laura Badaloni, "Asociacionismo empresario y conflictividad social en la Rosario de Entreguerras", en Sandra Fernández y Oscar Videla (Comp.) Ciudad Oblicua: aproximaciones a temas e intérpretes de la entreguerra rosarina, La Quinta Pata y Camino, Rosario, 2008. Así como también, debe mencionarse para un periodo previo al abordado en este artículo el trabajo de Adriana Pons y Oscar Videla, "Una corporación frente a la cuestión social: la Bolsa de Comercio de Rosario ante los conflictos obreros a principios del Siglo XX", en Anuario 15, Escuela de Historia, Facultad de Humanidades y Artes, UNR, Rosario 1991 - 92.

6 Natalia Alarcón, “Capital extranjero, corporaciones y política en Rosario. El caso de la huelga de los obreros de la Unión Telefónica del Río de la Plata a fines de los veinte", Coordenadas. Revista de Historia Local y Regional (4) 2, 2017. Disponible en: [http://ppct.caicyt.gov.ar/index.php/coordenadas/article/view/12157].

7 Adriana Pons, "La huelga tranviaria de 1928/9 en Rosario. Entre la coacción y el consenso", Ponencia II Jornadas Internacionales de Problemas Latinoamericanos Contemporáneo, Universidad Nacional de Córdoba, Córdoba, 2010.
} 
en las particulares características de la organización sindical de los trabajadores tranviarios y el desarrollo específico de la huelga de julio de 1928. Para finalizar, con las repercusiones que tendrá la huelga de dichos obreros a nivel del Concejo Deliberante rosarino, visualizando las diversas posturas y disputas políticas que se suscitarán en su seno respecto de esta huelga en particular.

\section{El movimiento obrero rosarino}

Hacia finales de 1920 la ciudad de Rosario contaba con aproximadamente 400.000 habitantes, siendo una de las ciudades más importantes de la República Argentina. Una ciudad que se había creado y fortalecido gracias al impulso de su puerto agroexportador, con un movimiento obrero que desde comienzos del siglo XX había sido protagonista de importantes luchas y poseedor de intensa capacidad de movilización social.

Durante la década de 1920, tanto anarquistas, comunistas, socialistas y sindicalistas revolucionarios militaban en el seno del movimiento obrero rosarino pero, eran los anarquistas, quienes dado el control de uno de los gremios más importantes de la ciudad como el de los estibadores portuarios quienes fueron los protagonistas del proceso de reorganización sindical en la urbe durante 1928.

Los gremios anarquistas de Rosario se nuclearon en torno a la Federación Obrera Local Rosario (FOLR) ${ }^{8}$ como el Sindicato de Obreros Portuarios, Conductores de Carros y Camiones, Sociedad de Capataces del Puerto, Obreros de Refinería Argentina, Obreros Cerveceros, Obreros de la Unión Telefónica, Obreros de la Pavimentación, Obreros Metalúrgicos, obreros de la Casa Minetti, Aserradores, Sindicato de Obreros Bolseros, Casa Bunge y Born, Obreros Casa Wilson y Cía, entre otros.

Los comunistas junto con los socialistas se sumaron a nivel local a la conformación de la Unión Obrera Local (UOL), adherida a la Unión Sindical Argentina de tendencia mayoritariamente sindicalista. Para 1928 dentro los principales gremios nucleados en esta organización se encontraban el sindicato de Ebanistas y Anexos, Conductores y Guardas de ómnibus, tranviarios, obreros carpinteros, Empleados de Comercio, Marítimos, pintores y gráficos.

Los gremios donde los comunistas tendrán un peso importante los encontraremos fuertemente organizados recién para la década de $1930^{9}$ pero su proceso de constitución comenzará en la década del '20 militando dentro de la UOL. Los principales bastiones comunistas de la ciudad eran los gremios de los obreros ebanistas y los gráficos, y hacia fines de la década de '20 se sumará el trabajo dentro del frigorífico Swift. ${ }^{10}$ Sin embargo, el

\footnotetext{
8 La FOLR era una central obrera rosarina que surgió a principios de siglo XX con la unión de anarquistas y socialistas como FOL para al poco tiempo ser hegemonizada por los libertarios. En 1912 se formó la FOLR adherida a la Federación Obrera Regional Argentina (FORA).

9 Gabriela Águila, “Los comunistas y el movimiento obrero en Rosario, 1943-1946”, en Anuario No14, a Escuela de Historia, Facultad de Humanidades y Artes, Rosario, UNR, 1991-1992. Alejandro Cingolani y Roberto Frutos, El partido Comunista y el movimiento obrero en los '30, Seminario Regional, Facultad de Humanidades y Artes, UNR, Rosario, 2003.

10 Paulo Menotti, "Maximalismo y organización. El papel de los comunistas en el movimiento obrero del sur santafesino frente a los conflictos sociales de 1917/21 y 1928", Ponencia presentada XII Jornadas
} 
peso de la UOL a nivel local era relativo, ya que una parte importante de los sindicatos funcionaba de forma autónoma ${ }^{11} \mathrm{o}$ bien se encontraban adheridos a la FOLR.

Al mismo tiempo, los Círculos Obreros tenían una incidencia nada desdeñable en el mundo del trabajo rosarino promoviendo la creación de sindicatos de trabajadores en su interior. Tal como sostiene Martín, la sindicalización católica mostraba dos facetas: una positiva, que consistía en procurar que los obreros se organizaran a fin de alcanzar, con su propio esfuerzo, la "justicia social" que requerían; y una de sentido negativo o de reacción, procurando que la misma se convirtiera en el contrapeso del sindicalismo de carácter revolucionario. ${ }^{12}$ En este sentido los primeros sindicatos católicos en la ciudad fueron el de los obreros tranviarios y el de Empleados y Dependientes del Comercio.

\section{Antecedentes para un conflicto}

Luego de años de relativa calma en lo que respecta a reclamos obreros, 1928 marcó el comienzo serie de huelgas que tuvieron como epicentro a la ciudad de Rosario y que luego se extendieron hacia las áreas rurales.

Todos los movimientos que se desencadenaron durante este período presentaron como disparador común el reclamo por cuestiones salariales, el mejoramiento en las condiciones de trabajo y la discusión sobre la provisión de la mano de obra, el cual constituyó un reclamo central dentro de muchas de las huelgas que se tuvieron lugar en esta coyuntura.

En este contexto se desarrollaron los conflictos de mayo de 1928 que tuvieron como principal protagonista a los estibadores del puerto, dicho conflicto adquirió tal magnitud, que se convirtió no sólo en el puntapié inicial de una serie de huelgas que afectaron a la ciudad durante el periodo, sino que también como derivación de la misma se llevaron a cabo sucesivas manifestaciones, enfrentamientos callejeros y acciones conjuntas con otros trabajadores.

La coyuntura político-electoral también presentó una creciente complejización. La división interna dentro de la Unión Cívica Radical (UCR) a nivel nacional entre personalistas y antipersonalistas trajo como consecuencia un importante reacomodamiento en la política santafesina. Durante el mes de mayo cuando estalló el primer gran conflicto en la ciudad 13 , el radicalismo antipersonalista representado en la provincia de Santa Fe por los unificados estaba claramente en retirada de las posiciones de poder.

Interescuelas/Departamentos de Historia. Departamento de Historia, Facultad de Humanidades y Centro Regional Universitario Bariloche, Universidad Nacional del Comahue, San Carlos de Bariloche, 2009.

11 Sindicatos Autónomos, Tranviarios, Sindicato de Chauffeurs y guardas de ómnibus, Obreros Pintores, Obreros Gráficos, Albañiles, Obreros Municipales, Industria Textil, yerbateros, Verduleros Unidos, Panaderos, Vidrieros, Sindicato de Chauffeurs de Taxis.

12 María del Carmen Pía Martín, Iglesia católica, cuestión social y ciudadanía, Rosario-Buenos Aires, 1892-1930, Tesis de Doctorado, Doctorado en Humanidades y Artes. Mención Historia Escuela de Postgrado Facultad de Humanidades y Artes Universidad Nacional de Rosario, 2012.

13 A principios del mes de mayo de 1928, los estibadores del puerto de la ciudad de Rosario se declararon en huelga, solicitando el aumento de salarios y el reconocimiento patronal de su sindicato, a través de un pliego de condiciones presentado el día 3 de mayo. 
Con miras a las elecciones para la gobernación de 1928, el yrigoyenista (personalista) Pedro Gómez Cello buscó su postulación tejiendo alianzas con diversos sectores del altamente fragmentado radicalismo, entre los que se encontraban seguidores de Ricardo Caballero ${ }^{14}$, otros yrigoyenistas disidentes opositores y varios miembros del Partido Demócrata Progresista recientemente pasados a las filas radicales.

La ascendencia de Caballero en el resultado de las elecciones del mes de febrero de 1928 a favor de Gómez Cello fue fundamental debido tanto a su estrecha relación con Hipólito Yrigoyen como por su particular discurso, que combinaba tendencias obreristas con criollismo y nacionalismo. La utilización de estos tópicos por parte de éste tenía que ver con algunos de los principios propugnados por el radicalismo que buscaba la exaltación de los valores criollos y populares tradicionales como parte de la esencia nacional, solo que, en este caso, articulados con la explicita reivindicación de la representación política de los obreros.

Por otra parte, las elecciones nacionales realizadas en el mes de abril otorgaron un importante triunfo a Hipólito Yrigoyen, a lo que debemos sumarle las elecciones municipales donde los radicales yrigoyenistas desplazaron como mayoría a los representantes del Partido Demócrata Progresista en el Concejo Deliberante.

Finalmente, a comienzos del mes de mayo cuando la huelga portuaria estaba en sus inicios, Gómez Cello designó a Ricardo Caballero como Jefe de Policía de la ciudad. En este sentido, no podemos dejar de mencionar que el regreso de figuras políticas consideradas obreristas a los organismos de poder tanto a nivel local, provincial y nacional 15 incrementó el clima de confianza entre las filas obreras. En un contexto de conflictividad obrera en ascenso, la interpelación a los obreros desde las facciones radicales y fundamentalmente de los caballeristas, hicieron que, en el contexto electoral, las acusaciones contra el "personalismo" por su incitación a la clase obrera fueran recurrentes.

No obstante, a medida que la conflictividad social fue en ascenso, y teniendo en cuenta, la postura adoptada por los caballeristas a través de su política de apoyo al

14 Nace en 1876, se recibe como médico en Córdoba en 1902 y tiene cercanías durante esta época con círculos vinculados al anarquismo. Posteriormente pasa a residir en Rosario donde se convierte en militante del radicalismo teniendo activa participación en la revolución de 1905. Es electo Vicegobernador de la provincia de Santa Fe en 1912 y cumple una función clave en el ascenso de Hipólito Yrigoyen a la presidencia de la Nación. Es diputado nacional desde 1916-1919, cuando pasa a ocupar el puesto de senador nacional. Tiene un rol destacado en el Congreso, desde donde expresará sus ideas alrededor de la justicia social y la defensa histórica del federalismo y de Yrigoyen. En 1928, luego de un período en el cual su popularidad había declinado, retorna a Rosario, ocupando la jefatura política del gobierno yrigoyenista de Gómez Cello. Caballero se destacará por su activa intervención en la ola de huelgas que se produce durante todo el año 1928, intervención en la que tiene una postura totalmente favorable a los obreros. Este factor promoverá la movilización social, disgustando a la burguesía rosarina y provocará en diciembre del mismo año, la intervención militar de la provincia y la renuncia de Caballero de su cargo. Luego de esto, se distanciará del yrigoyenismo y, tras el golpe de 1930, será uno de los tantos radicales que apoyarán el proyecto político de Agustín P. Justo. Cfr. Oscar Videla -Eduardo Zanella (comp.), Cuestión social, radicalismo y revisionismo en Ricardo Caballero, Buenos Aires, Imago Mundi, 2004.

15 Esta relación ha sido reseñada en los trabajos de Matthew Karush, "Radicalismo y conflicto obrero urbano 1912-1930", en Oscar Videla, Nueva historia de Santa Fe. Tomo IX. El siglo XX. Problemas sociales, politicas de Estado y economías regionales: 1912-1976, Rosario, Prohistoria ediciones- La Capital, Roberto Korzeniewicz, "The Labor Politics of Radicalism: The Santa Fe Crisis of 1928", en Hispanic American Historical Review, 73:1, Durham, Duke University Press, 1993; Joel Horowitz, El Radicalismo y el movimiento popular, (1916-1930), Buenos Aires, Sudamericana, 2015. 
movimiento obrero, hizo que la heterogénea alianza que había llevado a Gómez Cello a la gobernación comenzara a desintegrarse. Surgiendo a mediados de junio, una escisión conocida como el "Núcleo"16, que integrada por figuras como Alcides Greca, Jorge Raúl Rodríguez, José Benjamín Ábalos y José Guillermo Bertotto ${ }^{17}$ se constituyó como oposición dentro del propio partido a fin de contrarrestar la creciente influencia de Ricardo Caballero. Haciendo efectiva la escisión en noviembre de ese mismo año cuando Caballero decidió presentarse con lista propia en las elecciones municipales en la ciudad de Rosario, en las cuales el "Núcleo" tuvo una victoria ajustada sobre los "caballeristas". 18

\section{La ciudad de Rosario y los servicios públicos}

Entre 1881 y 1890, el Municipio de Rosario contrató la realización de importantes obras de infraestructura urbana. Durante este periodo, capitales principalmente británicos invirtieron en las áreas de transporte, comunicaciones y servicios como electricidad, gas y aguas corrientes. Sin embargo, cuando los efectos de la crisis económica de 1890 se retrajeron, inversiones francesas y belgas comenzarán a competir con las británicas.

Ya para 1890 el Municipio de Rosario contaba con servicio de teléfonos brindado por la Compañía Unión Telefónica del Río de La Plata ${ }^{19}$, luego se contrataron los servicios de cloacas y aguas corrientes. En 1892, el servicio eléctrico estaba en manos de la Compañía de Electricidad y Tracción del Río de la Plata, la cual pasó en 1910 a manos de la Sociedad de Electricidad de Rosario20, vinculada al holding Sofina. El 14 de septiembre de 1905, la Cie. Mutuelle de Tramways y la Union Anversoise de Tramways fundaron la Compagnie Générale de Tramways Electriques de Rosario (Compañía General de Tranvías eléctricos de Rosario), el grupo belga formado por las compañías Anversoise de Tranways et d'Enterprises Electriques de Amberes, Mutuelle de tramways y Banco Comptoir de la Bourse adquirirán las 5 redes de tranvías "hipomóbiles" que existían en Rosario: Tranway Ciudad del Rosario; Tranway AngloArgentino, Tranway Rosarino del Norte, Tranway del Saladillo y Tranways del Oeste. También

\footnotetext{
16 Luego denominado UCR Junta Reorganizadora.

17 Figuras más cercanas al reformismo liberal que a los idearios caballeristas.

18 "Fue batido el oficialismo en Rosario" 12936 Irigoyenistas, Demócratas 10431, Caballeristas 11763. El Orden, $17 / 11 / 1928$.

19 La United River Plate Telephone Company (Unión Telefónica del Río de la Plata), surgió en 1887, de la fusión de diversas empresas de capital extranjero: la Société du Pantéléphone L. de Locht et Cie. (francesa), la Compañía de Teléfono Gower-Bell (inglesa) y la Compañía Telefónica del Río de La Plata (norteamericana). Llevándose a cabo la aprobación de sus estatutos el 14 de abril de 1887. La Unión Telefónica del Río de la Plata, prestó servicios telefónicos en la Argentina bajo administración inglesa durante 43 años, hasta 1929 año en que pasó a manos norteamericanas cuando fue adquirida por la International Telephone and Telegraph company. Compañía Unión Telefónica del Río de la Plata, Cincuenta años de vida de la Cía. Unión Telefónica del Río de la Plata, 1887-1937, Buenos Aires, 1937.

${ }^{20}$ La ordenanza N 2 de 1902 concedió la explotación de la electricidad por cincuenta años a la Compañía de Electricidad y Tracción del Río de la Plata. Esta empresa pertenecía al grupo Morrison, que administraba el sistema de agua corriente y cloacas y poseía acciones en el Ferrocarril Central Argentino. En pocos años, la firma cambió de manos dos veces: la primera en 1907 y la segunda en 1910. Una cláusula de este mismo acuerdo de estipulaba que el servicio de electricidad era extensible a la tracción tranviaria.
} 
habían obtenido la concesión de la electrificación y explotación de estas redes, que suponían un total de 106 kilómetros de vías cuya concesión finalizaba en 1960. ${ }^{21}$

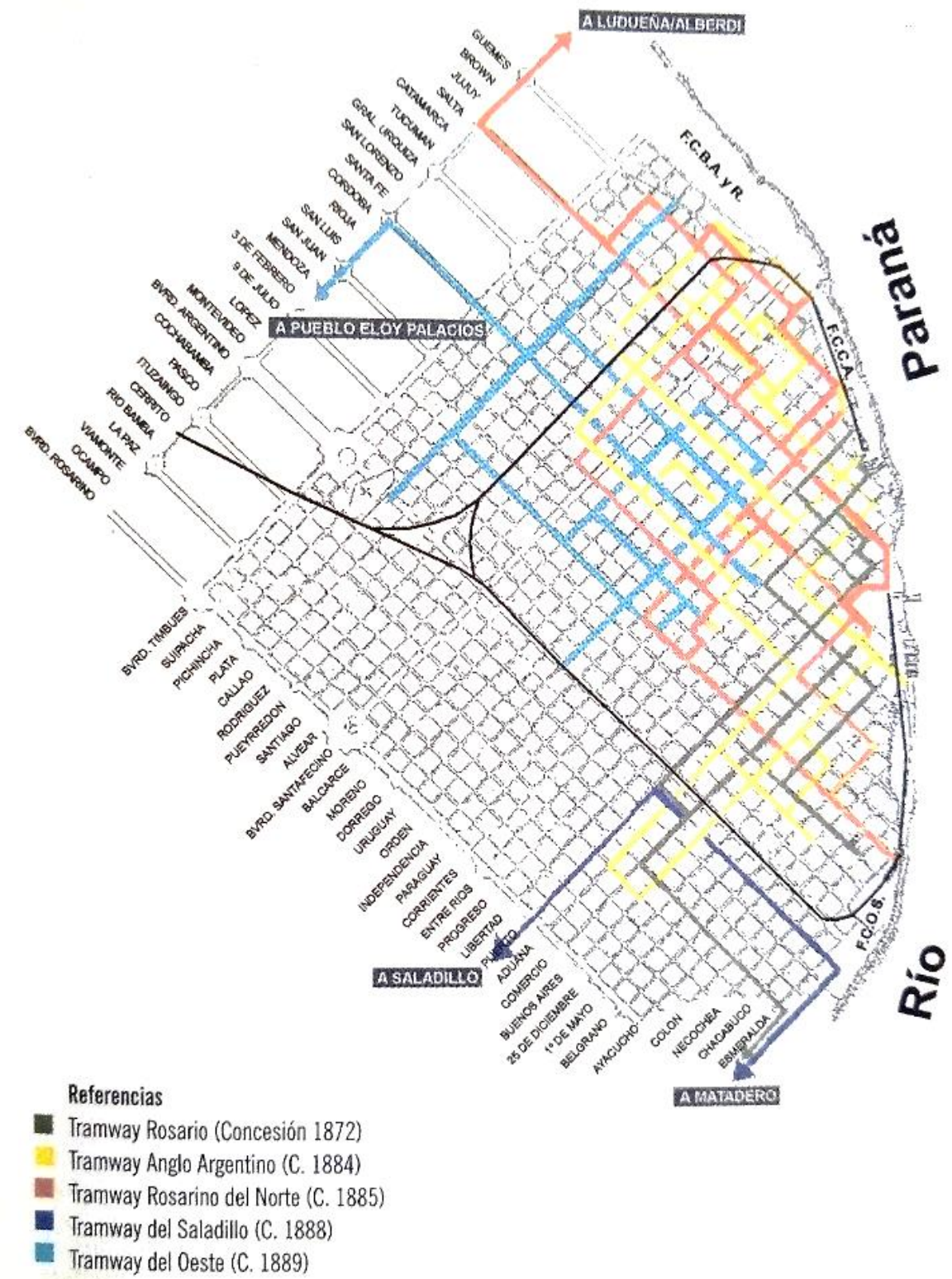

Fuente: Extraído de LANCIOTTI, Norma, De rentistas a empresarios. Inversión inmobiliaria y urbanización en la pampa argentina. Rosario, 1880-1914, Santa Fe, Universidad Nacional del Litoral, 2009.

21 Jean Louis Moreau, "Grupos belgas y servicios públicos en Argentina”, en Bart De Groof (eds.) En los deltas de la memoria. Bélgica y Argentina en los Siglos XIX y XX, Leuven University Press, 1998. 
Entre 1880 y 1948 las urbes más pobladas de la Argentina, entre ellas la ciudad de Rosario adoptaron el sistema de prestación indirecta de gestión de los servicios urbanos (concesión), donde la producción estaba a cargo de empresas privadas, y la responsabilidad y contralor dependía de la administración municipal. Dichas concesiones para la construcción de las obras y su explotación a largo plazo variaban entre los 30 a 70 años y una vez finalizada la misma, se transferían sus instalaciones a la órbita de la municipalidad.

En el caso de la empresa de tranvías y la Compañía de Electricidad la municipalidad de Rosario recibía un porcentaje de los ingresos brutos de las empresas, un 7\% sobre los ingresos de la empresa de tranvías, y 5\% sobre los ingresos de la Compañía de Electricidad, y la municipalidad se reservaba el control de las tarifas y de la calidad del servicio prestado.

Asimismo, la Sociedad de Electricidad de Rosario (SER) poseía un contrato explícito con la Compañía General de Tranvías Eléctricos de Rosario (CGTER), por el cual la primera de estas sólo podía proveer exclusivamente de corriente eléctrica a la CGTER.

La empresa tranviaria fue rápidamente rentable registrando una facturación siempre creciente: 2 millones en 1905, 2,8 en 1908, 5,4 en 1911 y 6 millones en vísperas de la Primera Guerra Mundial.22 La guerra apenas afectó a la marcha de la empresa y durante la primera década de los años de 1920, los beneficios aumentaron considerablemente, como consecuencia de los importantes beneficios obtenidos en el cambio de moneda. Pero al mismo tiempo, durante este periodo el municipio se ausentó de la fiscalización y control de los servicios públicos.

En los años subsiguientes las deficiencias en el servicio comenzaron a ser patentes, la Compañía General de Tranvías Eléctricos de Rosario era renuente a establecer aumentos en la frecuencia, invertir en el robustecimiento de la infraestructura y el material rodante o extensiones de vías y recorridos, consolidando una mala relación entre el público y el gobierno local. ${ }^{23}$

Dadas las necesidades de una urbe en expansión y las constantes irregularidades de la concesionaria, llevó a que la Municipalidad licitara la ampliación de la red tranviaria en 1924. Sin embargo, no se presentaron oferentes obligando años después a renegociar la concesión con la Compañía General de Tranvías Eléctricos de Rosario, en términos nada favorables para la Municipalidad y extendiendo la duración de la misma hasta el año 1965.

La Compañía Tranviaria contaba para 1928 con 170 coches para prestar servicio en la ciudad, los cuales no eran suficientes para cubrir las necesidades de una ciudad como Rosario. Asimismo, la concesionaria solía retirar coches que realizaban recorridos menos rentables y los derivaba hacia lugares en los cuales podía obtener mayores ganancias, dejando sobre todo a barrios suburbanos sin servicio en una clara violación al contrato de concesión. ${ }^{24}$

A fin de subsanar las falencias del transporte el poder municipal implantó un sistema de ómnibus de automóvil, constituyendo al mismo tiempo una reacción a la concesión otorgada a la Compañía de Tranvías. Las licencias para el transporte de ómnibus fueron concedidas a diversos empresarios que se presentaron libremente y cuya única garantía era

22 Jean Louis Moreau, op. Cit., 117.

23 Roldán, op. Cit., 91.

${ }_{24}$ Municipalidad de Rosario, Diarios de Sesiones del Concejo Deliberante de Rosario (DSCDR), Julio 29 de 1928, $3^{\circ}$ Sesión Extraordinaria, pp. 340-341. 
un depósito en el Banco Municipal de Préstamos. Asimismo, los recorridos, horarios y tarifas fueron responsabilidad de los empresarios, la Municipalidad sólo se reservó la potestad de aprobarlos, dadas estas medidas los recorridos de los ómnibus no se diferenciaban de los tranviarios y en la búsqueda de maximizar sus beneficios los empresarios superpusieron las trayectorias compitiendo directamente con los tranvías en lugar de funcionar como un servicio complementario.

El incremento en la cantidad de ómnibus en la ciudad fue progresivo y entre 1925 a 1926 la cantidad de unidades en circulación pasaron de treinta y cinco a ciento setenta y seis en sólo un año, expansión que fue calificada como "explosiva" en la Memoria de la Intendencia Municipal presentada en ese último año. ${ }^{25}$

Para 1927 se estimaba que el servicio de ómnibus había mermado en más de un cincuenta por ciento los ingresos de la Compañía de Tranvías Eléctricos:

La instalación del servicio de ómnibus ha beneficiado enormemente a la población, afectando en más de un cincuenta por ciento, las entradas de la empresa tranviaria. Pero como la inspección general de la municipalidad, cedió toda clase de tolerancia a los empresarios, los coches funcionan sin horario, ni higiene, carentes de medios de seguridad. 26

\begin{tabular}{|c|c|}
\hline $\begin{array}{c}\text { Progresión de la cantidad de ómnibus en circulación en la ciudad } \\
\text { de Rosario } \\
\text { Cantidad de unidades }\end{array}$ \\
\hline $\mathbf{A n ̃ o}$ & 17 \\
\hline $\mathbf{1 9 2 4}$ & 35 \\
\hline 1925 & 176 \\
\hline 1926 & 205 \\
\hline 1927 & 242 \\
\hline 1928 & 289 \\
\hline 1929 & 321 \\
\hline 1930 & 343 \\
\hline 1931 & \\
\hline
\end{tabular}

\section{La organización sindical de los tranviarios}

La historia de los conflictos laborales entre la compañía tranviaria y sus empleados tienen inicios tempranos en la ciudad de Rosario, remontándose el primero de ellos a fines del año 1912, 27 cuando los motormen y guarda coches presentaron un pliego de condiciones por mejoras salariales y jornadas de ocho horas. La huelga perduró durante cuatro días,

25 Municipalidad de Rosario, Memoria presentada al H. C. Deliberante por el intendente municipal Dr. Manuel E. Pignetto, s/e, Rosario, 1926.

26 Santa Fe, 29/03/1927.

27 La huelga es declarada el 29 de noviembre de 1912. 
concluyendo favorablemente para los trabajadores siendo decisivo el arbitraje del intendente Daniel Infante, quien aplicó la normativa municipal que exigía a la empresa garantizar el servicio público y no contratar motormen sin licencia.

Un resurgimiento de las protestas se producirá en abril de 1913, 28 el origen de esta huelga estuvo dado a raíz de la presentación y aprobación por parte del Concejo Deliberante de Rosario de los horarios de invierno para los tranvías que incluía una importante reducción del servicio afectando directamente a los trabajadores con esta decisión, la cual formaba parte de una represalia por parte de la empresa en búsqueda de debilitar al sindicato. La huelga terminó fruto de la represión ejercida por las tropas nacionales enviadas a la ciudad y con la desestructuración de la organización gremial de los tranviarios.

Finalmente, en la coyuntura de 1917 y sumándose a la conflictividad social ascendente en la ciudad e influidos por la prédica de la Federación Obrera Ferrocarrilera (FOF), ${ }^{29}$ los tranviarios estaban intentando rearmar su sindicato apoyados por la FOF local y en búsqueda de mejorar sus condiciones de trabajo presentaron a la empresa un pliego reivindicativo en el que se exigía la regulación de los horarios de trabajo y el reconocimiento de la entidad sindical. ${ }^{30}$

Los trabajadores del Ferrocarril Central Argentino y los del Central Córdoba paralizaron sus actividades conjuntamente con los tranviarios, logrando finalmente obtener las reivindicaciones reclamadas. Sin embargo, más tarde los obreros tranviarios desestructuraron su organización gremial eligiendo el liderazgo de los católicos nucleados en el Círculo Obrero de Rosario (COR), el cual constituía una agrupación sindical pro patronal, conformando uno de los primeros sindicatos católicos en la ciudad.

Este gremio de tranviarios llegó a contar 487 afiliados un año después de su creación en 1918, tal como sostiene María Pía Martín esta cifra llama la atención si se tiene en cuenta que la Federación Obrera Marítima ${ }^{31}$ en la ciudad de Rosario registraba 450 cotizantes para

\footnotetext{
28 El 20 de abril de 1913 comenzó una nueva huelga de tranviarios. Sobre las huelgas de tranviarios de 1912-1913 en Rosario ver: Alex Ratto, “El Partido Socialista frente a las huelgas rosarinas de 1912-1913”, Coordenadas. Revista de Historia Local y Regional (4) 2, 2017. Santiago Javier Sánchez, "La intendencia de Daniel Infante en Rosario (1912-1913): las paradojas de un socialista español", en Historia Regional, Sección Historia, ISP No 3, Año XVIII, $\mathrm{N}^{\mathrm{o}} 23,2005$.

29 Federación Obrera Ferrocarrilera (FOF), organización sindical que agrupaba a los trabajadores ferroviarios que se desempeñaban en los talleres, redes viales y obras, a los señaleros y al personal de tráfico.

30 Paulo Menotti y Antonio Oliva, “El poder de la turba. La lucha de los ferroviarios del Central Argentino y las contiendas del poder gremial en el seno del movimiento obrero (1917-1918)", en Revista Archivos No6, 2015. Disponible en:

http://www.archivosrevista.com.ar.ca1.toservers.com/contenido/wp-content/uploads/2015/03/MenottiOliva.pdf

31 La Federación Obrera Marítima fue creada del 5 de abril de 1910, conformada por foguistas, marineros, mozos y otros trabajadores de sala de máquinas, cubierta y cocina, organizando la estructura federativa del gremio marítimo, que agrupaba diversas secciones y sociedades por categoría y región geográfica, se combinó con cierto grado de centralismo, dando como resultado un sindicato único que fortaleció la posición de los trabajadores frente a la patronal. La actitud legalista y crecientemente negociadora del sindicalismo, plasmada en su práctica sindical al frente del gremio marítimo, se desarrolló a partir de la creciente aceptación de la acción estatal en las relaciones laborales. Laura Caruso, "Huelga a bordo: los orígenes de la FOM en 1910 y el sindicalismo revolucionario", en REMS, Año 5/6, 2012/2013. Disponible en: https://estudiosmaritimossociales.org/wpcontent/uploads/2014/01/rems-nc2ba-5-6-dossier-
} 
el año 1918. ${ }^{2}$ Asimismo, esta autora hace referencia a que la mayoría de estos tranviarios tenían como único presentador a Bartolomé Morra,33 miembro de la Comisión de Propaganda del COR; otros habían sido presentados por diversos socios y algunos figuraban inscriptos "por la Empresa de Tranvía Eléctrico".

A la figura de Bartolomé Morra la encontraremos vinculada a la gestión municipal rosarina, para 1919 lo veremos ocupando una banca en el Concejo Deliberante, también formará parte del "Centro La Propiedad" (CLP) 34 junto con otro concejal de la ciudad perteneciente al Partido Demócrata Progresista, Esteban Morcillo. Ya para la década del ' 40 lo hallaremos en la dirección de la Empresa Mixta de Transporte (EMTR), institución que surgirá durante la intendencia de Esteban Morcillo a partir de la municipalización del transporte público de la ciudad producto de la conflictiva relación establecida entre el municipio y la CGTER.

Para 1919 el Círculo Católico de Obreros que dirigía el sindicato de tranviarios nucleaba a 492 obreros $^{35}$, ya para 1925 los trabajadores del transporte urbano estaban fragmentándose y en 1928, los tranviarios reorganizaron su gremio al calor de la conflictividad laboral que tuvo su origen en la huelga de estibadores portuarios, nucleándose a nivel local en la Unión Obrera Local (UOL), adherida a la Unión Sindical Argentina de tendencia mayoritariamente sindicalista donde militaron junto con los comunistas. ${ }^{36}$

Este gremio fue poseedor de un importante peso a nivel local dada su capacidad de paralizar la ciudad al ser su principal medio de transporte. Al mismo tiempo, no eran desconocidas las degradantes condiciones de trabajo a las que estaban sujetos los obreros tranviarios, no contaban con el descanso semanal establecido por la ley de 190537, sus

\footnotetext{
32 Martín, op. Cit., 304.

33 Bartolomé Morra, nació en La Spezia, Italia, fue monaguillo en Turín, llegó a Rosario a los 15 años, enviado por Don Miguel Rúa, Primer Sucesor de Don Bosco. Fue alumno del colegio salesiano San José y miembro activo del Círculo Católico de Obreros.

34 Durante la década de 1920, surgen en la ciudad de Rosario una serie de sociedades y asociaciones fomentistas que plantean proyectos urbanísticos a gran escala sobre la ciudad y a la vez presionar sobre los poderes municipales para que intervengan. Ejemplo de este auge lo constituyen algunas asociaciones urbanísticas que nuclean a propietarios de bienes raíces, como por ejemplo el Centro La Propiedad, creado en abril de 1920, conformado por una conjunción de intereses desde ciertos sectores privados asociados a la arquitectura, al urbanismo y desarrollo inmobiliario. Si bien, tal como señala Ronen Man, no podemos asegurar las vinculaciones entre el CLP y la Liga Patriótica Argentina (LPA), un hecho no menor es que en 1921 el periódico de la LPA, Patria y Orden, tuviera su sucursal de redacción y administración en Córdoba 940, siendo la misma dirección que declarará la sede del CLP desde 1920 a 1933, lo cual puede marcar un indicio de la tendencia política que esgrimían sus socios. Ronen Man, "Sociabilidad rosarina de entreguerras, el oximorón de un urbanismo patriótico”, en Sandra Fernández (dir.) La ciudad en movimiento. Espacio público, sociedad y política. Rosario 1910-1940, ISHIR-CONICET, Rosario, 2012.

35 Martín, op. Cit., pp. 314-315.

36 "La célula Comunista tranviaria está desplegando una gran actividad jugando sus componentes un papel importantísimo en el movimiento". La Internacional, 05/07/1928. Los comunistas mostraron una gran originalidad al implementar diversos mecanismos para la lucha de clases a estos mecanismos Camarero los llamó "repertorios organizacionales". El principal de ellos era el de la celularización como unidad básica del partido. Hernán Camarero, A la conquista de la clase obrera. Los comunistas y el mundo del trabajo en la Argentina 1920-1935, Buenos Aires, Siglo XXI, 2007.

37 El 6 de setiembre de 1905, el Senado y la Cámara de Diputados de la Nación sancionaron la Ley número 4661 de Descanso Dominical.
} 
salarios estaban por debajo del mínimo. Además, por cualquier tipo de falta, como infracciones de tránsito, denuncias de los pasajeros o errores en su trabajo se le aplicaba al trabajador multas que implicaban grandes descuentos en sus salarios.

Dado este contexto, el 2 de julio de 1928 los trabajadores de Compañía General de Tranvías Eléctricos de Rosario emiten un pliego de condiciones cuyos principales reclamos eran: el reconocimiento por parte de la Empresa de Tranvías Eléctricos de Rosario de la Federación de Tranviarios Unidos de Rosario; la aceptación y creación de una comisión de reclamos que se encargue de solucionar los asuntos suscitados entre la empresa y los obreros; jornada de ocho horas; franco semanal; efectividad a todo el personal con seis meses de antigüedad; aumento de un $10 \%$ del jornal cada cinco años; entre otros. ${ }^{38}$ Dándole a la compañía un plazo de veinticuatro horas para dar una respuesta. Ante el rechazo de la patronal 1800 trabajadores se declararán en huelga, dejando así a la ciudad sin su principal medio de transporte.

Esa misma semana, el gerente interino de la compañía residente en la ciudad de Rosario, siguiendo órdenes del Directorio anunció que ese mismo día se reestablecería el servicio, realizando un comunicado a los obreros que habían abandonado sus tareas.

La respuesta por parte de los trabajadores fue dispar algunos concurrieron a la usina para reanudar el trabajo, otros hicieron caso omiso de ello. Al momento de intentar retomar el servicio se produjeron diversas agresiones "determinándose una falta de garantías", lo que obligó a que el paro se prolongara. 39

Al mismo tiempo, para ilustrar estos hechos de violencia, la falta de garantías imperante y como un modo de obtener el apoyo de la opinión pública en general, la Compañía de Tranvías Eléctricos, enviará una nota al diario La Capital registrando en él, hasta el más mínimo detalle, el nombre de los agresores y de los agredidos, lugares donde ocurrieron los hechos. Por otro lado, destacaban: "en las inmediaciones de esta repartición, toda la noche han estado grupos numerosos de huelguistas armados impidiendo terminantemente el acceso del personal a estas dependencias." 40

En este punto, la concesionaria de servicio intentó desplazar el foco de atención hacia la culpabilización del Jefe de Policía de la ciudad Ricardo Caballero, ${ }^{41}$ que no brindaba las garantías necesarias para el restablecimiento del servicio. Reforzando esta actitud, los directores de la Compañía de Tranvías solicitaron al Intendente Municipal que la autoridad policial prestara la vigilancia necesaria para garantizar la libertad de trabajo. Era una práctica común en huelgas anteriores que la policía o los bomberos circularan en las unidades custodiando la seguridad de sus conductores, práctica a la cual se resistían a continuar implementando las autoridades rosarinas.

Esta solicitud tiene que ver con la exigencia patronal respecto de la "libertad de trabajo", la cual implicaba para la Compañía de Tranvías la defensa de sus derechos

\footnotetext{
38 La Capital, 25/06/1928.

39 La Capital, 06/07/1928.

40 La Capital, 06/07/1928.

41 Este cargo, aunque con el nombre de Jefe Político (en la coyuntura el título se cambió por el de Jefe de Policía), había sido creado en 1854, era designado directamente por el gobernador de la provincia y tenía a su cargo publicar, circular, ejecutar y hacer que se ejecuten las leyes, órdenes y disposiciones que dictamine el Ejecutivo de la Provincia; custodiar el orden y sosiego público; proteger las personas y las propiedades.
} 
patronales de imponer sus condiciones en el lugar de trabajo y, por otro lado, el derecho de demandar al Estado la protección de sus bienes y del personal adicto a través de la utilización de la fuerza pública en los momentos de huelga. Sin embargo, el Jefe de Policía determinó que lo que se dispondría sería de un servicio especial de patrullas para que pueda efectuarse la circulación de los coches. ${ }^{42}$

El accionar de Caballero en la ciudad de Rosario vino a modificar drásticamente las relaciones entre patrones y obreros, lo que le reportó numerosos enemigos, ya que desde un primer momento sostuvo que la intervención policial debía deshacerse de toda función represiva para ocuparse de tareas de persuasión y mediación. Él sostenía que no era posible "imponer la solución del problema social por la fuerza, o por la acción exclusiva de una clase". 43

Para el día doce de julio, el Ejecutivo municipal conmina a la empresa al cumplimiento del contrato, dándole un plazo de veinticuatro horas para la reanudación del servicio. Ese mismo día y en un clima social muy agitado, se declara otra huelga de servicios públicos, la de los obreros de la Unión Telefónica del Río de la Plata.

Una vez más ante la imposibilidad de retomar el servicio, el gobierno municipal convoca a las partes en conflicto a fin de arribar a una solución. Sin embargo, dicha reunión no arrojó resultados favorables. 44

En un intento por solucionar la huelga de manera particular dos concejales de la ciudad pertenecientes al Partido Demócrata Progresista, Esteban Morcillo ${ }^{45}$ y José N. Antelo46, entablan conversaciones con los obreros en huelga y la empresa concesionaria del servicio, logrando un pliego de condiciones que fue virtualmente aceptado por las partes. El mismo consistía: la compañía acepta que los obreros constituyan sindicato, pero no reconocerá la personería de esta asociación para tratar con la compañía cuestiones que tuvieran que ver con el personal; la reincorporación del personal despedido; se comprometía a no ejercer actos de represalias; efectivización del personal luego de seis meses de antigüedad; jornada de ocho horas; aumento del $10 \%$ en los salarios actuales. ${ }^{47}$

El 19 de julio los habitantes de la ciudad de Rosario amanecieron con la esperanza de ver solucionado el conflicto tranviario dadas las actuaciones del día anterior. Sin

42 La Capital, 12/07/1928.

43 Ricardo Caballero, Los conflictos sociales de la ciudad de Rosario y su zona agrícola 1928, Memorial elevado al gobierno provincial, Rosario, s/e, 1928.

44 La Capital, 15/07/1928.

45 Esteban Morcillo conocido partidario del PDP, concejal, vicepresidente del Concejo Municipal, Intendente de Rosario durante el período 1932 - 1933, será socio de buena parte de los clubes de elite del periodo tales como el Club Español. En 1932 cuando concluyó la intervención de la provincia que decretara el gobierno surgido del golpe militar de 1930, el gobernador electo, Luciano Molinas, lo nombró al frente del Ejecutivo local. La gestión de Esteban Morcillo como intendente de Rosario contó con un gran número de obras acordes a la imagen de ciudad activa, siendo sus mayores logros la municipalización del alumbrado público y del transporte, creando a tal fin la Empresa Mixta de Transporte con privilegios monopólicos. Sumando a esto, la iniciativa de La Vivienda del Trabajador. Retirado de la actividad política, junto a otro empresario, fundó un comercio de gran envergadura en el ramo ferretería llamado "Echeverría y Morcillo".

46 Antelo era también una de las figuras clave del PDP, concejal, diputado nacional por la provincia de Santa Fe (1931), Ministro de Gobierno, Justicia y Culto durante el gobierno de Luciano Molinas, candidato a gobernador por la provincia para las elecciones de 1940.

47 La Capital, 19/07/1928. 
embargo, la empresa concesionaria no firmó el pliego de condiciones y solicitó al Municipio la rebaja en el porcentaje del siete por ciento que pagaba la Compañía como contribución a la comuna a un cuatro por ciento, y si esto se efectivizaba, recién allí podrían acordar el aumento del diez por ciento en los salarios ${ }^{48}$

Al cumplirse veintidós días de suspensión del servicio tranviario, la intendencia ${ }^{49}$ emitió una resolución conminatoria para que la empresa de tranvías reanudara el servicio bajo pena de que, si no se diera cumplimiento a lo ordenado, la Municipalidad podría incautar los instrumentos de servicio e instalaciones de la compañía para reanudar por su cuenta la circulación de los coches, convocando a estos fines a sesiones extraordinarias al Concejo Deliberante.

Asimismo, tal como afirma Roberto Korzeniewicz, 50 dados los conflictos obreros que se estaban sucediendo en Rosario, el presidente Alvear ${ }^{51}$ consideró la posibilidad de intervenir la provincia de Santa Fe y enviar tropas federales a la ciudad, pero debido a la aplastante derrota que sufrieron los candidatos antipersonalistas, este carecía del capital político necesario para tomar cualquier decisión que pudiera ser interpretada como un ataque a los Personalistas. Al mismo tiempo el presidente entrante, Yrigoyen, buscaba asegurarse una transición tranquila y no avalaría cualquier medida drástica que pudiera costarle el apoyo de sus seguidores en una provincia clave como Santa Fe. Provocando con esta dinámica el aumento de la autonomía de los líderes provinciales en relación al gobierno Nacional.

\section{La huelga tranviaria y su repercusión en el Concejo Deliberante}

El 27 de julio el Concejo Deliberante rosarino comenzaba sus sesiones extraordinarias para discutir las acciones a tomar, frente a lo cual imperaron dos propuestas: por un lado, la incautación inmediata de la compañía mediante un proyecto elaborado por los concejales José Perfumo y Francisco Mazza de la Unión Cívica Radical Comité Nacional (Caballerista), la cual era apoyada por el concejal del Partido Socialista Independiente (PSI) y por parte del Radicalismo Unificado, y por otro, la opción propuesta por los partidarios del Partido Demócrata Progresista (PDP) de nombrar un tribunal arbitral para la solución del conflicto y si esto no se conseguía, recién allí proceder a la intervención.

Los concejales del PDP tomarán una postura cautelosa respecto de apoyar la incautación de la concesionaria, solicitando que primeramente se agoten todos los medios posibles para que el conflicto sea resuelto por las partes. Por un lado, no podían negar la

48 La Capital, 22/07/1928.

49 En este momento la intendencia municipal era ejercida por Ángel Enghel (15/05/1928 al 07/08/1928). La designación del Intendente Municipal constituía una potestad del Ejecutivo provincial, lo cual restaba al ejercicio del cargo entidad representativa. Con el ascenso de Pedro Gómez Cello al gobierno de la provincia se desató una importante disputa entre los partidarios de Ricardo Caballero y Armando Antille por ganar la intendencia municipal de la ciudad de Rosario, lo cual refrendaría su poder en la provincia. A poco de finalizar la huelga tranviaria el ejecutivo municipal pasará a manos de Tobías Arribillaga (07/08/1928 al 24/2/1930), radical yrigoyenista y caballerista.

50 Korzeniewicz, op. cit., 6.

51 Marcelo Torcuato de Alvear, presidente de la Nación Argentina entre el 12 de octubre de 1922 y 12 de octubre de 1928. 
justeza del reclamo obrero, tal como lo expresa Esteban Morcillo: "si ha habido alguna huelga justa es esta; porque se trata de una compañía que paga jornales verdaderamente irrisorios". 52

En el caso del conflicto con la empresa de tranvías eléctricos, constantemente hacen alusión a la legalidad de la situación amparando la medida en el análisis realizado por el especialista en derecho administrativo, Rafael Bielsa, ${ }^{53}$ con el cual tanto concejales del PDP como de la UCR y el PSI tuvieron conversaciones respecto de la legalidad de la incautación.

Los concejales del PDP harán referencia constantemente a que las circunstancias, los había obligado a llegar a esa resolución, tal como lo expresaba el concejal Antelo: "Llegamos a la intervención sin deseo, sin interés de hacerla, al contrario, comprendiendo la enorme responsabilidad que asume la municipalidad al adoptar una actitud a la que las circunstancias la obligan imperiosamente". 54

Hasta los años '20, los debates sobre la municipalización de los servicios públicos no habían logrado instalarse en la tribuna pública pero sería a partir de los trabajos que elaboraron un grupo de juristas y economistas 55 , encabezados por el mismo Dr. Bielsa dentro de la Facultad de Ciencias Económicas, Comerciales y Políticas de la Universidad del Litoral, donde se llevaron a cabo los primeros análisis respecto de las implicancias legales y económicas de la municipalización de los servicios públicos. 56

El proyecto presentado por los concejales del PDP, lo que buscaba era la intervención de la empresa por parte del Municipalidad, dándole participación a la compañía por medio de veedores y luego, una vez restablecido el servicio, esta podría "reasumir el servicio tranviario en los términos de su concesión" 57 y el concejal Mattos afirmaba en este sentido: "les damos una participación [en referencia a la empresa tranviaria] que ustedes no les otorgan y reconocemos los derechos que tienen". 58

Al mismo tiempo, los partidarios del PDP se resistían a la incautación total de la Compañía tranviaria dada la existencia de un contrato explícito entre la Sociedad de Electricidad y la de tranvías, por el cual la primera de estas solo prestaría servicio de corriente eléctrica a la CGTER y la construcción de otra usina eléctrica costaría tanto como financiar la mitad de la red de electricidad existente en la ciudad, ${ }^{59}$ acarreando costos que eran imposibles de cubrir para el municipio.

52 DSCDR, Julio 29 de 1928, $3^{\circ}$ Sesión Extraordinaria.

53 Fue un destacado abogado y jurista, especialista en Derecho Administrativo. Al fundarse en 1920 la Universidad Nacional del Litoral, fue profesor de Derecho Administrativo en la Facultad de Ciencias Económicas, Comerciales y Políticas durante cuarenta años y decano desde 1949 a 1952, fecha en que fue separado del cargo por su oposición a Perón. A partir de 1921 fue secretario general de la Municipalidad de Rosario y entre 1931 y 1933 fue subsecretario del Ministerio de Justicia e Instrucción Pública de la Nación. Fue elegido presidente del Colegio de Abogados de Rosario para los períodos 1929-1930; 1931-1932 y 1934-1935.

54 DSCDR, Julio 29 de 1928, $3^{\circ}$ Sesión Extraordinaria, pág. 353.

55 Los integrantes de este grupo eran: Rafael Bielsa, Natalio Muratti y poco después, Manuel Cansino, Ángel Passerini y Francisco Bendicente.

56 Norma Lanciotti, Conflictos y Prácticas Institucionales en la configuración de la política municipal de servicios públicos. Rosario (Argentina), 1890-1930, Ponencia en Segundas Jornadas de Historia Regional Comparada, Pontificia Universidad Católica de Rio Grande do Sul, Porto Alegre, 2005.

57 DSCDR, Julio 29 de 1928, $3^{\circ}$ Sesión Extraordinaria, pág. 335.

58 DSCDR, Julio 29 de 1928, $3^{\circ}$ Sesión Extraordinaria, pág. 335. El subrayado es nuestro.

59 DSCDR, Julio 29 de 1928, $3^{\circ}$ Sesión Extraordinaria, pág. 345-347. 
Si bien el PDP, defendía la municipalización de los servicios públicos, punto siempre presente en su plataforma electoral, 60 para estos el énfasis estaba puesto en el ahorro presupuestario, en la eficacia administrativa y en el control de los contribuyentes. ${ }^{61}$

Al mismo tiempo, tal como sostenía el representante el PSI, Galaretto ${ }^{62}$, en esta huelga se movían otros intereses subyacentes:

La empresa, señores concejales, tiene también influencias de otro orden a su alcance; esta empresa, como otros, toma a su servicio gente influyente en nuestro mundo político y social, como lo prueba el hecho de que su actual abogado es un ex-intendente municipal, ex-senador provincial, exministro de la provincia, el doctor Oscar C. Meyer. ${ }^{63}$

Junto con Oscar Meyer ${ }^{64}$ otro de los abogados de la compañía fue el doctor Fermín Lejarza ${ }^{65}$ conocido partidario del PDP, íntimamente relacionado con la empresa de tranvías. Tanto que durante su posterior intendencia en la ciudad de Rosario entre 1931 y 1932, se verá envuelto en un escándalo por la concesión del servicio de transporte otorgado a la empresa belga. ${ }^{6}$

60 Carlos Malamud, “La evolución del Partido Demócrata Progresista y sus plataformas políticas, 1915-1946, en Anuario del IEHS, No 15, 2000.

61 Marcela Ternavasio, Municipio y política, un vínculo conflictivo, Tesis de Maestría, FLACSO, Bs. As., 1991.

62 La reforma del sistema electoral de 1927, que amplió el sistema político municipal supuso cambiar un padrón de contribuyentes (nativos y extranjeros) por otro que sumaba al padrón provincial, extranjeros inscriptos y mujeres (solo profesionales, maestras y contribuyentes) y aplicaba proporcionalidad por cociente, permitió que en las elecciones para el Consejo Deliberante de abril de 1928 la izquierda llegara por primera vez al Concejo, obteniendo los comunistas y los socialistas independientes una banca cada uno, cuestión que reflejaba el incremento del electorado izquierdista. Diego Roldán, "Formación y reforma del municipio", en Darío Barriera (Dir). Instituciones, gobierno y territorio. Rosario de la Capilla al Municipio (1725-1930), Rosario, ISHIR-CONICET, 2010. Oscar Videla, "Elecciones, partidos y conflicto social a finales de los años veinte del siglo XX en Rosario", en Revista Secuencia, (104), e1392, México, Instituto Mora, 2019. doi: https:/ / doi.org/10.18234/secuencia.

63 DSCDR, Julio 29 de 1928, $3^{\circ}$ Sesión Extraordinaria, pp. 337.

64 Político perteneciente a la Unión Cívica Radical Unificada (Antipersonalista), fue intendente de la ciudad de Rosario entre 9 de junio de 1913 y 7 de junio de 1915; formó parte del gobierno de Enrique Mosca y luego de Cepeda como Ministro de Hacienda y Diputado Nacional por la UCR.

65 Fermín Lejarza nació en Rosario en 1871. Estudió en el Colegio Nacional, donde fue Profesor e Instructor. Se graduó como Doctor en Leyes en la Universidad de Buenos Aires en 1894. Fue elegido presidente de la Junta Municipal de Rosario en 1909. Ejerció su profesión de abogado en asociación con su hermano Joaquín Lejarza. Fue miembro de la Junta Ejecutiva de la Liga del Sur (luego devenido en el Partido Demócrata Progresista) y de la Sociedad Rural, asimismo actuó como presidente del Club Social (1908-1914). Entre 1896 y 1932, se desempeñó como concejal municipal de Rosario, Jefe de policía, abogado del Banco Nación e intendente de la ciudad entre 1931-1932.

66 Al promediar 1931, la Compañía de Tranvías Eléctricos cortaba intermitentemente el servicio dándole visibilidad a sus reclamos por la merma registrada en la venta de sus pasajes, originada por la competencia de los ómnibus. Entonces, el intendente Fermín Lejarza fue compelido a expedirse sobre la ampliación de la concesión establecida en 1926. Sus relaciones profesionales y personales con la empresa y sus abogados le impidieron confeccionar un dictamen definitivo, limitándose a elevar los antecedentes del conflicto al interventor provincial. La resolución del interventor Arancibia Rodríguez se sometió a los intereses de la empresa, restituyendo el monopolio a la compañía tranviaria, estableciendo la inmediata caducidad de los permisos de ómnibus que vencían en 1934. Lejarza, se vio envuelto en un escándalo por supuestas irregularidades en el contrato. Aunque el plazo de la concesión era excesivo, las condiciones generales no eran 
En los discursos de los concejales del PDP, sus intervenciones sólo se remitieron a resaltar las exorbitantes ganancias de la empresa y en la necesidad de resolver el conflicto entre patrones y obreros para luego si fuera requerido, resolver la intervención. Esto tiene que ver, con la bandera que agitaba este partido de un municipio con atribuciones exclusivamente administrativas, dejando de lado cualquier tipo de conflicto que excediera esta órbita. ${ }^{67}$

Por otro lado, el discurso que emanaba de los concejales de la UCR era claramente obrerista y en cierto sentido anti imperialista, haciendo referencia a los abusos del capital extranjero sobre todo por parte de las empresas de servicios públicos de la ciudad. $68 \mathrm{Al}$ mismo tiempo, en sus discursos se ponía en relieve el nuevo papel asumido por las fuerzas policiales encabezadas por Ricardo Caballero, hecho que en gran medida colaborará al mantenimiento de la huelga por parte de los obreros tranviarios. Como sostiene José J. Perfumo:

Pido que, aunque sea por esta sola vez, nos olvidemos que somos de distintos sectores políticos para tratar este asunto con un solo criterio, que es el defendernos del enemigo común en este caso representado por una empresa que quiere olvidar el respeto que está obligada a tener a nuestra ciudad y a nuestras leyes.

Los señores concejales que se encuentran sentados en este recinto por la voluntad del pueblo, tienen la obligación de demostrar al mismo pueblo que los votara, que en ningún momento están dispuestos a permitir que las empresas a que explotan servicios públicos, confundan la misión de los poderes comunales, creyendo que deben permanecer en silencio y permitiendo toda clase de abusos (...)

(...) La empresa de tranvías eléctricos es de las que retribuyen en la forma más miserable los servicios que le prestan a sus obreros y empleados, y cuando esa pobre gente ha querido reclamar sus justos derechos a la vida, siempre ha contado con la complicidad o colaboración de la policía para obligar a sus obreros a volver al trabajo.

(...) Esta vez parece que no ha tenido resultado este sistema y entonces pretende quebrar la resistencia de su personal en huelga por medio de la miseria y el hambre $(. . .)^{69}$

Las empresas de capital extranjero que conformaban la infraestructura de servicios de la ciudad, habían ejercido durante años sus prerrogativas sin rendir cuentas a la comuna

demasiado diferentes a las de otras concesiones avaladas por el PDP desde el Concejo. Sin embargo, ante el revuelo público causado, el PDP no dudó en desligarse inmediatamente del asunto, atacando con dureza al interventor Arancibia Rodríguez -también vinculado al partido- y al propio Lejarza, en nombre de la "honestidad" y la "entereza" de la democracia progresista. Diego Mauro, "El fraude y la legitimidad de ejercicio. El PDP santafesino y las transformaciones del discurso político en las entreguerras", en IV Jornadas de Historia política: Argentina siglos XIX y XX, Centro de estudios de historia política, Universidad Nacional de San Martín, 2011.

67 Ternavasio, op.cit., 86.

68 Discurso que se tornará más efusivo un mes después cuando en el Concejo se trate la cuestión de la Compañía Telefónica. Alarcón, Op. Cit.

69 El subrayado es nuestro. DSCDR, Julio 29 de 1928, $3^{\circ}$ Sesión Extraordinaria, pág. 332-333. 
gracias a la laxitud del control municipal. Sin embargo, en un contexto altamente politizado como el de 1928, será cuando las huelgas de los obreros traigan a colación los términos de esos contratos revelando la oportunidad de utilizar la disputa de los obreros como un instrumento político para cosechar adhesiones.

No podemos negar que la figura del Jefe de Policía de la ciudad, Ricardo Caballero, será fundamental para desarrollo del movimiento huelguístico al desactivar todo tipo de función represiva por parte de las fuerzas policiales, fomentando en esta, tareas de mediación y persuasión.

En este sentido, el concejal Mattos (PDP) acusará al jefe de policía de una "participación electoralista", considerando que las medidas antirepresivas implementadas por este, y aún más, las medidas tomadas a favor de los obreros tenían un claro fin electoral. Utilizando esta alusión con un tono descalificativo, como si fuera demagogia, lo cual será reproducido tanto por la derecha política, como por la izquierda. ${ }^{70}$

(...) Es cierto, señor presidente, que el jefe político de este departamento ha tenido en este asunto una participación política o electoralista, mejor dicho; porque se padece actualmente del mal del electoralismo oficialista que a todo lo corrompe $(\ldots)^{71}$

La acusación será reproducida por el arco político y corporativo en general, aludiendo a la actuación que el Jefe de policía venía desplegando frente a las huelgas que se sucedieron en la coyuntura del 28 en la ciudad, señalando el uso político de los obreros por parte de esta figura. Efectivamente, la postura de Caballero tendrá sus réditos políticos meses más tarde, cuando se avecinen los comicios para la renovación del Concejo Deliberante y los mismos obreros tranviarios publiquen un manifiesto en apoyo a Caballero y a la Unión Cívica Radical Comité Nacional:

Por algo que todos conocemos i que ninguno de nosotros podemos olvidar, la deuda sagrada, que los obreros tranviarios reconocemos i esa es, en pago de la promesa del partido Radical auténtico, que nos dio hombres de la talla de Ricardo Caballero, cuya actuación al frente de la Jefatura Política, es el más grande ejemplo de la democracia i respeto, i que marcará los rumbos nuevos para los derechos de los débiles (...)

Obrero tranviario: Dad tu voto a quien te ofreció i te dio garantías para poder solucionar tus intereses i este fué el Partido Radical (Comité Nacional) i recuerda que de su estabilidad depende tu bienestar. ${ }^{72}$

Siguen más de trescientas firmas.

\footnotetext{
70 Esto será patente un mes después en los discursos tanto del representante del PC como del PSI en la discusión sobre la huelga que mantenían los obreros de la Unión Telefónica. DSCDR, Agosto 29 de 1928, 8 Sesión Extraordinaria, pp. 452.

71 DSCDR, Julio 29 de 1928, $3^{\circ}$ Sesión Extraordinaria, pp. 334.

72 El Nativo, 10/11/1928.
} 
Al mismo tiempo, hay que poner de relieve la participación en el debate por parte de representante del Partido Socialista Independiente, Rodolfo Galaretto ${ }^{73}$ :

La causa del conflicto es imputable exclusivamente a la empresa. Si hay una huelga justa, si hay un movimiento obrero legítimo, indispensable en la salvaguarda del nivel de vida de centenares de familias, es el que mantienen los tranviarios en esta ciudad; existe, como lo refleja el pliego de condiciones y ellos lo han denunciado, un régimen de trabajo realmente infame en nuestra empresa de tranvías, hay allí un régimen de multas que repugna a cualquier administrador honesto, un régimen de multas y de descuentos en pugna con una ley de la Nación, la ley 11.278 , de salarios que la compañía viola de continuo...

Carecen los obreros tranviarios del indispensable descanso hebdomadario, que se acuerda en la industria y el comercio a la gente que trabaja; no disfrutan del descanso semanal que establece la ley de la provincia, y que debe aplicarse en el servicio continuo de tranvías eléctricos.

(...) Esta misma compañía que paga sueldos de hambre a su personal, que es insensible a sus pedidos de mejoramiento, es la que lleva su contabilidad en idioma extranjero, no presenta balances al municipio y nos trata como a un país conquistado, como a una factoría que gobierna desde Amberes. 74

En principio es de resaltar dentro del debate, el profundo conocimiento que evidencia Galaretto de las condiciones de trabajo de los obreros tranviarios y de las leyes que la empresa de tranvías eléctricos no cumplía ante sus trabajadores, con un claro apoyo hacia la masa obrera. Otro punto interesante para destacar del discurso de Galaretto, es su impugnación a las empresas de capitales extranjeros, particularmente las empresas de servicios públicos locales como en este caso, la empresa de tranvías y así lo hará un mes después cuando se presente el debate sobre la empresa de teléfonos. ${ }^{75}$

Si bien, tal como plantea Oscar Videla ${ }^{76}$ en relación al accionar del concejal del PSI, en general promueve medidas y hace intervenciones a favor de los obreros, pero en general vota y/o apoya las iniciativas del PDP, lo que conlleva a que en ciertas ocasiones quede

\footnotetext{
73 Durante los años de 1918 y 1919, Rodolfo N. Galaretto, fue un activo propagandista y orador oficial tanto de la Federación Agraria Argentina como del Socialismo. El 26 de abril de 1919 se inauguró en Buenos Aires convocada por el PS - la I a Conferencia Socialista y Obrera Panamericana, ante la cual, fue designado representante de la Federación Socialista Santafesina. El 20 de agosto de 1921 cuando quedó definitivamente constituida la Cooperativa de Consumo que se había fundado el 22 de mayo, integró su primer Consejo de Administración. Por esa época, también integró el Consejo de Administración de la Cooperativa Obrera del Pan, con el cargo de secretario. Durante la década del '20, en varias oportunidades integró la Comisión de Prensa de la Federación Socialista Santafesina. En 1927 se separó del Partido e integró el Partido Socialista Independiente, en cuya representación fue electo concejal de Rosario en las elecciones del 29 de abril de 1928.

74 DSCDR, Julio 29 de 1928, $3^{\circ}$ Sesión Extraordinaria, pp. 336-337.

75 DSCDR, Agosto 29 de 1928, 8 Sesión Extraordinaria, pp. 453-454.

76 Oscar Videla, "Elecciones, partidos y política municipal a finales de los veinte en Rosario: la experiencia del Partido Socialista Independiente", ponencia presentada en Seminario permanente de formación y especialización disciplinar en historia argentina. Actores y conflicto. Prácticas y representaciones. Siglos XIX y XX, ISHIR-CONICET, Rosario, 2018
} 
vinculado a medidas rompehuelgas aunque envueltas discursivamente en la defensa de los trabajadores. Sin embargo, esto no impedirá que Galaretto vote en estas circunstancias a favor del proyecto presentado por los representantes de la Unión Cívica Radical Comité Nacional que solicitaba la incautación de la concesionaria, otorgándole al Municipio la responsabilidad de su administración. Refrendando con su apoyo uno de los puntos defendidos por el socialismo, la promoción de iniciativas que apuntaban a una participación más plena del Estado en la sociedad local en pos de la protección del sector más castigado, los trabajadores.

Luego de resuelta la intervención por parte del Concejo Deliberante, los concejales del PDP, Esteban Morcillo y José Antelo, reanudaron las gestiones para el arreglo intentando con esto que se dilatara la emisión del decreto del Ejecutivo municipal para dar cumplimiento a la incautación presentando un pliego de condiciones, el cual fue aceptado por la empresa concesionaria para luego ser puesto a consideración de los obreros.

No podemos dejar de reseñar, que durante las elecciones del mes de abril de 1928 donde se aplicó por primera vez la proporción por cociente, el PDP perderá la histórica mayoría que poseía desde 1909 en el Concejo Deliberante rosarino. El control de este cuerpo había sido no sólo una de las principales herramientas políticas del partido en sus confrontaciones con las diversas facciones radicales, sino claramente "el último reducto" institucional del mismo. ${ }^{77}$

Al perder el control de la mayoría en el Concejo a manos del radicalismo yrigoyenista, su posibilidad de acción quedó limitada a establecer algún tipo de acuerdo con los radicales unificados o lograr sacar rédito político de los continuos enfrentamientos entre los yrigoyenistas. Por tanto, la intervención de los concejales Antelo y Morcillo responderá al modo en el que el PDP se adaptará a esta nueva situación de minoría, operando por otros canales, en este caso en particular a partir del vínculo directo con los sindicatos y sus trabajadores, para lograr mantener la iniciativa política dentro del Concejo Deliberante.

Los tiempos para la aceptación del pliego se fueron dilatando, con lo cual el gobierno municipal advirtió que si no hubiese arreglo entre las partes en conflicto la Comisión Administradora nombrada por el intendente procedería a incautar el material de la empresa a fin de reestablecer el servicio.

Si bien, fue el Intendente municipal, Angel Enghel78, quien presentó y convocó al Concejo Deliberante para analizar la posibilidad de incautación a la empresa tranviaria, creemos que esta tenía como objetivo principal funcionar como un mero elemento de presión sobre la compañía belga a fin de que resolviera la situación con sus obreros, y por otro lado, demostrar que el municipio podía ejercer su papel de contralor como un modo de ejemplo para otras concesionarias de servicios públicos que operaban en la ciudad.

\footnotetext{
77 Videla, Op. Cit.

78 Angel Enghel, llegará a ocupar una banca en Concejo Deliberante a partir de la lista de la Unión Cívica Radical Comité Nacional, donde varias facciones de la UCR se unirán para enfrentar las elecciones de abril de 1928, no pudimos encontrar referencias que acreditaran su adscripción al caballerismo, asimismo luego de su interinato frente a la Intendencia municipal de Rosario entre el 15/05/1928 al 07/08/1928 no hemos registrado en las fuentes consultadas otra participación política por parte de esta figura. A días de finalizada la huelga de tranviarios será reemplazado en la intendencia por Tobías Arribillaga un reconocido radical caballerista.
} 
Finalmente, los obreros en huelga decidieron entrar a tratar directamente con la empresa, ya que había una propuesta muy aceptable, acordándose que el día 2 de agosto a primera hora se reanudarían las tareas de los limpiadores de vías y coches y que los motormen y guardas, lo harían a partir del día siguiente.

El convenio firmado, mantenía todas las cláusulas del pliego de condiciones presentado originalmente a la empresa concesionaria por parte de los concejales del PDP y que el Directorio de la empresa se había negado a refrendar a mediados del mes de julio.

\section{Consideraciones Finales}

De las numerosas huelgas que estallaron a lo largo de 1928 y que afectaron a los servicios públicos, el paro de actividades del personal de la Compañía de Tranvías Eléctricos presentó sus particularidades dada su duración y el juego que se estableció entre la firma prestadora y los poderes públicos locales.

Los nuevos tiempos vividos en la jefatura de policía de la ciudad, gracias a la incidencia de Ricardo Caballero y la desactivación de las funciones represivas por parte de la fuerza pública, fue percibido por parte de los obreros como una señal indiscutida del apoyo de Caballero al movimiento huelguístico (a pesar de que la conducción del gremio de los tranviarios era cercana a la Unión Sindical Argentina), hecho que fue refrendado por estos en los momentos previos a las elecciones municipales de noviembre cuando los mismos obreros publiquen un manifiesto de apoyo a Caballero y a su partido la Unión Cívica Radical Comité Nacional.

Por otro lado, la participación del intendente municipal fue paradigmática, ya que presentó y convocó al Concejo Deliberante para analizar la posibilidad de incautación a la empresa tranviaria, pero dada la dilación por parte del Ejecutivo en aplicar la resolución del Concejo, creemos que esta tenía como objetivo principal funcionar como un mero elemento de presión sobre la compañía belga a fin de que resolviera la situación con sus obreros, y por otro lado, funcionar como ejemplo para otras empresas concesionarias de servicios públicos que operaban en la ciudad.

Al mismo tiempo, es interesante resaltar los debates producidos en el seno del Concejo Deliberante por parte de los partidarios de la UCR refrendando un claro discurso de apoyo a la masa trabajadora a la cual buscaba interpelar directamente con miras a las futuras elecciones municipales. Más claro en este sentido, fue la participación en el debate del representante del PSI con un claro posicionamiento pro obrerista y anti imperialista que hizo que en este caso uniera voluntades con la UCR yrigoyenista a fin de lograr la incautación de la compañía, apelando a la municipalización de los tranvías eléctricos en pos de mejorar el servicio y las condiciones de sus trabajadores.

Por otro lado, el conflicto dejó entrever la estrecha relación existente entre los dirigentes del PDP y la empresa concesionaria, ya sea intentando "proteger" los intereses de esta, buscando que el proyecto de incautación no afectara los derechos de la misma e incluso cuando la incautación era un hecho, pudieron evitarla operando directamente sobre los sectores trabajadores y empresarios al lograr la resolución del conflicto.

La ambigüedad en el discurso del PDP se hizo evidente puesto que programáticamente el partido defendía la municipalización de los servicios públicos. Sin 
embargo, esta postura debió ser "matizada" en el discurso de los concejales en pos de los derechos de la concesionaria que fueron enmascarados discursivamente en tópicos que apoyaban los justos reclamos de los trabajadores.

Es de destacar en este contexto la capacidad de organización y resistencia demostrada por los trabajadores, capitalizando en su beneficio la tensión que la huelga había desatado en el ámbito político de la ciudad, teniendo en cuenta la amplia resonancia que la misma tuvo en el Concejo Municipal. De esta manera, luego de prácticamente un mes sin servicio tranviario, la huelga culminaría por la presión ejercida desde el poder municipal a partir de la sanción del decreto de incautación de los materiales de la compañía y por la finalmente exitosa intermediación de los concejales del PDP.

La conflictiva relación entre la CGTER y el municipio de Rosario terminó en 1932 cuando se creó la Empresa Municipal Mixta de Transporte del Rosario, sobre la fusión de capitales públicos y privados, constituyendo la primera municipalización del servicio de transporte público en la Argentina.

\section{Referencias bibliográficas}

Adrián Ascolani, El sindicalismo rural en la Argentina. De la resistencia clasista a la comunidad organizada (1928-1952), Bernal, UNQ, 2009.

Adriana Pons, "La huelga tranviaria de 1928/9 en Rosario. Entre la coacción y el consenso", Ponencia II Jornadas Internacionales de Problemas Latinoamericanos Contemporáneo, Universidad Nacional de Córdoba, Córdoba, 2010.

Alejandro Cingolani y Roberto Frutos, El partido Comunista y el movimiento obrero en los '30, Seminario Regional, Facultad de Humanidades y Artes, UNR, Rosario, 2003.

Alex Ratto, "El Partido Socialista frente a las huelgas rosarinas de 1912-1913", Coordenadas. Revista de Historia Local y Regional (4) 2, 2017.

Carlos Malamud, "La evolución del Partido Demócrata Progresista y sus plataformas políticas, 1915-1946, en Anuario del IEHS, No 15, 2000.

Compañía Unión Telefónica del Río de la Plata, Cincuenta años de vida de la Cía. Unión Telefónica del Río de la Plata, 1887-1937, Buenos Aires, 1937.

Diego Roldán, "Formación y reforma del municipio", en Darío Barriera (Dir). Instituciones, gobierno y territorio. Rosario de la Capilla al Municipio (1725-1930), Rosario, ISHIR-CONICET, 2010.

Eduardo Sartelli, "Mecanización y conflicto social en la llanura pampeana. Santa Fe y la huelga de braceros en 1928", en Adrián Ascolani, (comp.) Historias del sur santafesino, Rosario, Ed. Platino, 1993.

Fernando Cesaretti, Diego Mauro y Hernán Uliana, “Representaciones, prensa y conflicto social. Estrategias complejas en el diario La Capital, mayo - julio de 1928", en Marta Bonaudo (dir.) Imaginarios y prácticas de un orden burgués. Rosario, 1850 - 1930, Los actores entre las palabras y las cosas, Rosario, Prohistoria, 2005.

Gabriela Águila, "Los comunistas y el movimiento obrero en Rosario, 1943-1946", en Anuario No14, a Escuela de Historia, Facultad de Humanidades y Artes, Rosario, UNR, 19911992. 
Hernán Camarero, A la conquista de la clase obrera. Los comunistas y el mundo del trabajo en la Argentina 1920-1935, Buenos Aires, Siglo XXI, 2007.

Jean Louis Moreau, "Grupos belgas y servicios públicos en Argentina", en Bart De Groof (eds.) En los deltas de la memoria. Bélgica y Argentina en los Siglos XIX y XX, Leuven University Press, 1998.

Joel Horowitz, El Radicalismo y el movimiento popular, (1916-1930), Buenos Aires, Sudamericana, 2015.

Laura Caruso, "Huelga a bordo: los orígenes de la FOM en 1910 y el sindicalismo revolucionario", en REMS, Año 5/6, 2012/2013. Disponible en:

https:/ / estudiosmaritimossociales.org/wp-content/uploads/2014/01/rems-nc2ba-5-6dossier-

Marcela Ternavasio, Municipio y política, un vínculo conflictivo, Tesis de Maestría, FLACSO, Bs. As., 1991.

María del Carmen Pía Martín, Iglesia católica, cuestión social y ciudadanía, Rosario-Buenos Aires, 1892-1930, Tesis de Doctorado, Doctorado en Humanidades y Artes. Mención Historia Escuela de Postgrado Facultad de Humanidades y Artes Universidad Nacional de Rosario, 2012.

Marianela Scocco, Representaciones de la huelga de portuarios. Rosario, mayo de 1928. Una perspectiva desde el acontecimiento, Seminario Regional, Escuela de Historia, Rosario, UNR, 2009.

Matthew Karush, "Radicalismo y conflicto obrero urbano 1912-1930", en Oscar Videla, Nueva historia de Santa Fe. Tomo IX. El siglo XX. Problemas sociales, políticas de Estado y economías regionales: 1912-1976, Rosario, Protohistoria, ediciones La Capital

Natalia Alarcón, "Capital extranjero, corporaciones y política en Rosario. El caso de la huelga de los obreros de la Unión Telefónica del Río de la Plata a fines de los veinte", Coordenadas. Revista de Historia Local y Regional (4) 2, 2017. Disponible en: [http://ppct.caicyt.gov.ar/index.php/coordenadas/article/view/12157].

Natalia Alarcón, "Corporaciones empresarias, política y conflicto obrero en los prolegómenos de la crisis", Tesis de Licenciatura, Escuela de Historia, Facultad de Humanidades y Artes, Universidad Nacional de Rosario, 2017.

Norma Lanciotti, “Las relaciones entre gobierno municipal y empresas de servicios públicos en argentina: Un estudio de caso, Rosario 1887-1910", en Anuario de Espacios Urbanos, México, Universidad Autónoma Metropolitana-Azcapotzalco, 2002.

Norma Lanciotti, Conflictos y Prácticas Institucionales en la configuración de la política municipal de servicios públicos. Rosario (Argentina), 1890-1930, Ponencia en Segundas Jornadas de Historia Regional Comparada, Pontificia Universidad Católica de Rio Grande do Sul, Porto Alegre, 2005

Oscar Videla -Eduardo Zanella (comp.), Cuestión social, radicalismo y revisionismo en Ricardo Caballero, Buenos Aires, Imago Mundi, 2004.

Oscar Videla, "Elecciones, partidos y conflicto social a finales de los años veinte del siglo XX en Rosario", en Revista Secuencia, (104), e1392, México, Instituto Mora, 2019. doi: https:/ / doi.org/10.18234/ secuencia.

Oscar Videla, “Elecciones, partidos y política municipal a finales de los veinte en Rosario: la experiencia del Partido Socialista Independiente", ponencia presentada en Seminario 
permanente de formación y especialización disciplinar en historia argentina. Actores y conflicto. Prácticas y representaciones. Siglos XIX y XX, ISHIR-CONICET, Rosario, 2018

Paulo Menotti y Oscar Videla, "Las huelgas de los estibadores portuarios en el sur santafesino en 1928", en Sociohistórica, $N^{\circ}$ 32, 2 do. Semestre de 2013. Disponible en: http://www.sociohistorica.fahce.unlp.edu.ar/

Paulo Menotti, “Maximalismo y organización. El papel de los comunistas en el movimiento obrero del sur santafesino frente a los conflictos sociales de 1917/21 y 1928", Ponencia presentada XII Jornadas Interescuelas/Departamentos de Historia. Departamento de Historia, Facultad de Humanidades y Centro Regional Universitario Bariloche, Universidad Nacional del Comahue, San Carlos de Bariloche, 2009.

Ricardo Caballero, Los conflictos sociales de la ciudad de Rosario y su zona agrícola 1928, Memorial elevado al gobierno provincial, Rosario, s/e, 1928.

Roberto Korzeniewicz, "The Labor Politics of Radicalism: The Santa Fe Crisis of 1928”, en Hispanic American Historical Review, 73:1, Durham, Duke University Press, 1993

Ronen Man, "Sociabilidad rosarina de entreguerras, el oximorón de un urbanismo patriótico", en Sandra Fernández (dir.) La ciudad en movimiento. Espacio público, sociedad y política. Rosario 1910-1940, ISHIR-CONICET, Rosario, 2012.

Santiago Javier Sánchez, "La intendencia de Daniel Infante en Rosario (1912-1913): las paradojas de un socialista español", en Historia Regional, Sección Historia, ISP No 3, Año XVIII, No 23, 2005.

\section{Fuentes}

Prensa periódica

La Capital, Rosario

La Internacional, Buenos Aires

El Nativo, Rosario

\section{Documentos públicos y privados}

Centro Unión Almaceneros de Rosario, Acta de la Comisión Directiva, No 728, junio de 1928. Municipalidad de Rosario, Compendio de Digesto Municipal año 1931, Talleres Gráficos Pomponio, Rosario, 1931.

Municipalidad de Rosario, Diarios de Sesiones del Concejo Deliberante de Rosario Municipalidad de Rosario, Digesto Municipal. Ordenanzas, Decretos y Reglamentos de la Municipalidad del Rosario dictados durante el año 1924, Imprenta de JB Ravani Rosario, 1929. Municipalidad de Rosario, Digesto Municipal. Ordenanzas, Decretos y Reglamentos de la Municipalidad del Rosario dictados durante el año 1925, Imprenta de JB Ravani, Rosario, 1930. Municipalidad de Rosario, Digesto Municipal. Ordenanzas, Decretos y Reglamentos de la Municipalidad del Rosario dictados durante el año 1926, Imprenta de JB Ravani, Rosario,1930. Municipalidad de Rosario, Memoria presentada al H. C. Deliberante por el intendente municipal Dr. Manuel E. Pignetto, s/e, Rosario, 1926. 